An Experimental and Modeling-Based Study into the Ignition Delay Characteristics of Diesel Surrogate Binary Blend Fuels

M. A. Carr, P. A. Caton, L. J. Hamilton, J. S. Cowart, M. Mehl, W. J. Pitz

July 21,2011

ASME IC Engine 2011 FallTechnical Conference Morgantown, WV, United States October 2, 2011 through October 5, 2011 
This document was prepared as an account of work sponsored by an agency of the United States government. Neither the United States government nor Lawrence Livermore National Security, LLC, nor any of their employees makes any warranty, expressed or implied, or assumes any legal liability or responsibility for the accuracy, completeness, or usefulness of any information, apparatus, product, or process disclosed, or represents that its use would not infringe privately owned rights. Reference herein to any specific commercial product, process, or service by trade name, trademark, manufacturer, or otherwise does not necessarily constitute or imply its endorsement, recommendation, or favoring by the United States government or Lawrence Livermore National Security, LLC. The views and opinions of authors expressed herein do not necessarily state or reflect those of the United States government or Lawrence Livermore National Security, LLC, and shall not be used for advertising or product endorsement purposes. 


\section{AN EXPERIMENTAL AND MODELING-BASED STUDY INTO THE IGNITION DELAY CHARACTERISTICS OF DIESEL SURROGATE BINARY BLEND FUELS}

\author{
Matthew A. Carr \\ U.S. Naval Academy \\ Annapolis, MD, USA \\ Jim S. Cowart \\ U.S. Naval Academy \\ Annapolis, MD, USA
}

\author{
Patrick A. Caton \\ U.S. Naval Academy \\ Annapolis, MD, USA \\ Marco Mehl \\ LLNL \\ Livermore, CA, USA
}

\author{
Leonard J. Hamilton \\ U.S. Naval Academy \\ Annapolis, MD, USA \\ William J. Pitz \\ LLNL \\ Livermore, CA, USA
}

\section{ABSTRACT}

This study examines the combustion characteristics of a binary mixture surrogate for possible future diesel fuels using both a single-cylinder research engine and a homogeneous reactor model using detailed chemical reaction kinetics. Binary mixtures of a normal straight-chain alkane (pure n-hexadecane, also known as n-cetane, $\mathrm{C}_{16} \mathrm{H}_{34}$ ) and an alkyl aromatic (toluene, $\mathrm{C}_{7} \mathrm{H}_{8}$ ) were tested in a single-cylinder research engine. Pure nhexadecane was tested as a baseline reference, followed by $50 \%, 70 \%$, and $80 \%$ toluene in hexadecane blends. Testing was conducted at fixed engine speed and constant indicated load. As references, two conventional petroleum-based fuels (commercial diesel and US Navy JP-5 jet fuel) and five synthetic Fischer-Tropsch-based fuels were also tested. The ignition delay of the binary mixture surrogate increased with increasing toluene fraction and ranged from approximately 1.3 $\mathrm{ms}$ (pure hexadecane) to $3.0 \mathrm{~ms}$ ( $80 \%$ toluene in hexadecane). While ignition delay changed substantially, the location of $50 \%$ mass fraction burned did not change as significantly due to a simultaneous change in the premixed combustion fraction. Detailed chemical reaction rate modeling using a constant pressure, adiabatic, homogeneous reactor model predicts a chemical ignition delay with a similar trend to the experimental results, but shorter overall magnitude. The difference between this predicted homogeneous chemical ignition delay and the experimentally observed ignition delay is defined as the physical ignition delay due to processes such as spray formation, entrainment, mixing, and vaporization. On a relative basis, the addition of $70 \%$ toluene to hexadecane causes a nearly identical relative increase in both physical and chemical ignition delay of approximately 50\%. The chemical kinetic model predicts that, even though the addition of toluene delays the global onset of ignition, the initial production of reactive precursors such as $\mathrm{HO}_{2}$ and $\mathrm{H}_{2} \mathrm{O}_{2}$ may be faster with toluene due to the weakly bound methyl group. However, this initial production is insufficient to lead to wide-scale chain branching and ignition. The model predicts that the straight-chain alkane component (hexadecane) ignites first, causing the aromatic component to be consumed shortly thereafter. Greater ignition delay observed with the high toluene fraction blends is due to consumption of $\mathrm{OH}$ radicals by toluene. Overall, the detailed kinetic model captures the experimentally observed trends well and may be able to provide insight as to the relationship between bulk properties and physical ignition delay.

\section{INTRODUCTION}

Conventional petroleum hydrocarbon-based fuels for diesel engines can be characterized as mixtures of five different hydrocarbon classes: straight-chain (normal) alkanes, branched (iso-) alkanes, cyclic alkanes, aromatic, and alkene hydrocarbons. Diesel fuel has been shown to have approximately equal amounts of straight-chain alkanes, aromatics, and cyclic alkanes with a minority fraction of branched alkane species [1]. Jet fuel is also operated in diesel engines by the military and has been shown to contain over $50 \%$ straight and branched alkanes, with another $25 \%$ of the fuel coming from cyclic alkanes (mono-, di- and tri-). The final minority fraction (up to $25 \%$ ) was shown to be aromatic species $[2]$. 
The molecular structure and makeup of newer alternative fuels, such as FT and HRD, differ in important ways from conventional petroleum-based hydrocarbon diesel fuels. While the Fischer-Tropsch (FT) fuel conversion process offers the opportunity to produce liquid hydrocarbon (HC) fuels for transportation from alternative sources (e.g. natural gas or coal), all FT synthetic fuels are not created equal [3]. FT fuels are comprised of principally of normal and branched alkanes. Both of these $\mathrm{HC}$ fuel structures have lower density than aromatic compounds, and thus FT fuels have lower densities overall when compared with conventional petroleum diesel and jet fuels. The lack of sulphur and aromatic content often causes FT synthetic fuels to be characterized as "cleaner" due to the absence of these two important particular matter precursors.

Alternative diesel and jet engine fuels produced from hydrotreating renewable sources have begun to receive attention in recent years [4]. These fuels are also principally composed of a normal and branched paraffins. HVO fuels, produced from hydrotreating renewable biological oils, typically have a similar molecular structure to FT fuels [5]. The absence of aromatics and cyclo-alkanes causes FT and HVO fuels to have a higher cetane number than petroleum-based diesel fuels [6].

The US Navy is looking into hydrotreated algae oil as a diesel fuel replacement as well as hydrotreated camelina oil (mustard seed, Camelina sativa) as a jet fuel replacement. These HVOs are not the ester-based biodiesel of recent years, but rather pure hydrocarbon fuels with no molecularly bound oxygen [7]. Very little published engine experimental work has been performed on HVO based fuels [8].

While the lack of aromatic content may help reduce precursors for soot formation, these aromatic species also will have an important effect on the physical mixing process, the chemistry leading to ignition, and even the lubricating properties of the fuel, which affect fuel pump durability. Other concerns exist as well, such as the interaction of elastomeric seals with the aromatic species in the fuel. For these reasons, some addition of aromatic species are likely to enhance fuel system component durability [9]. Understanding the effects of these aromatic species on the physical process of air and fuel mixing, and the chemical processes leading to ignition, are important in order to ensure compatibility with legacy and future diesel engines. Due to the low cetane nature of aromatic fuel species, it is critical to understand the limits of aromatic content in diesel fuel and to determine to what extent aromatic content addition affects the combustion characteristics of a diesel engine.

In a previous study [10] the authors developed simple binary diesel fuel surrogates using normal hexadecane with both toluene and isododecane. Variations of these blends were tested in a CFR engine in order to understand the resulting combustion characteristics. This study showed that significant volume fractions of toluene (and isododecane) were required to slow down ignition delay significantly. This present study will use these experimental toluene-hexadecane results, in conjunction with detailed chemical kinetic modeling, in an effort to better understand and predict both the chemical and physical ignition delay period of paraffinic hydrocarbon fuels with increasing aromatic content.

It is widely appreciated in the diesel engine research community that diesel engine combustion is complex and difficult to predict analytically. The transient multi-phase reacting environment is highly heterogeneous. While detailed modeling of diesel combustion is often pursued (particularly in conjunction with physical modeling of emission formation mechanisms), the objective of this study is to attempt to decouple physical processes (such as the vaporization, entrainment, and mixing processes in the diesel jet) from the chemical processes (such as the initial reactions that eventually lead to chain branching and bulk fuel ignition). The goal of the present study is to determine the mechanisms that limit addition of aromatic species to paraffinic diesel fuel, and to develop the basis of tools that could be utilized to predict the future viability of as-yet-unknown HRD-based alternatives to petroleum-based diesel fuel.

\section{EXPERIMENT}

\section{Engine and Data Acquisition}

\section{Table 1: Experimental engine parameters}

\begin{tabular}{|l|l|}
\hline Type & $\begin{array}{l}\text { Indirect-injection diesel, pancake- } \\
\text { style chamber, in-line cam-driven } \\
\text { pump }\end{array}$ \\
\hline Bore & $82.6 \mathrm{~mm}$ \\
\hline Stroke & $114 \mathrm{~mm}$ \\
\hline Speed & 900 RPM fixed \\
\hline Compression Ratio & $18: 1$ \\
\hline Coolant & water reflux, $100^{\circ} \mathrm{C}$ \\
\hline Intake Air & Lab ambient, $20^{\circ} \mathrm{C}$ \\
\hline Fuels & $\begin{array}{l}\text { n-hexadecane }\left(\mathrm{C}_{16} \mathrm{H}_{34}\right)-\text { baseline } \\
\text { toluene } \\
(50 \%, 70 \%, 80 \% \text { by vol. }) \\
\text { commercial diesel }\end{array}$ \\
& $\begin{array}{l}\text { U.S. Navy JP-5 } \\
\text { synthetic }(\mathrm{FT}-\text { based) diesel and jet } \\
\text { fuels }\end{array}$ \\
\hline
\end{tabular}

The engine used in this study is a standard single-cylinder Cooperative Fuels Research (CFR) diesel test engine. The speed is fixed with a motoring/absorbing dynamometer at 900 RPM. The engine allows variable compression ratio, injection 
timing, and injection amount. Table 1 lists the basic specifications of this engine and the operating conditions used in this study. A Kistler ${ }^{\mathrm{TM}} 6125 \mathrm{~B}$ pressure transducer was mounted in the engine head. Airflow was measured with a Meriam $^{\text {TM }}$ Laminar Flow Element (LFE). A line diagram of the engine configuration is shown in Figure 1. Data were collected with a National Instruments ${ }^{\mathrm{TM}}$ LabView data acquisition system sampling at a rate of $50 \mathrm{kHz}$.

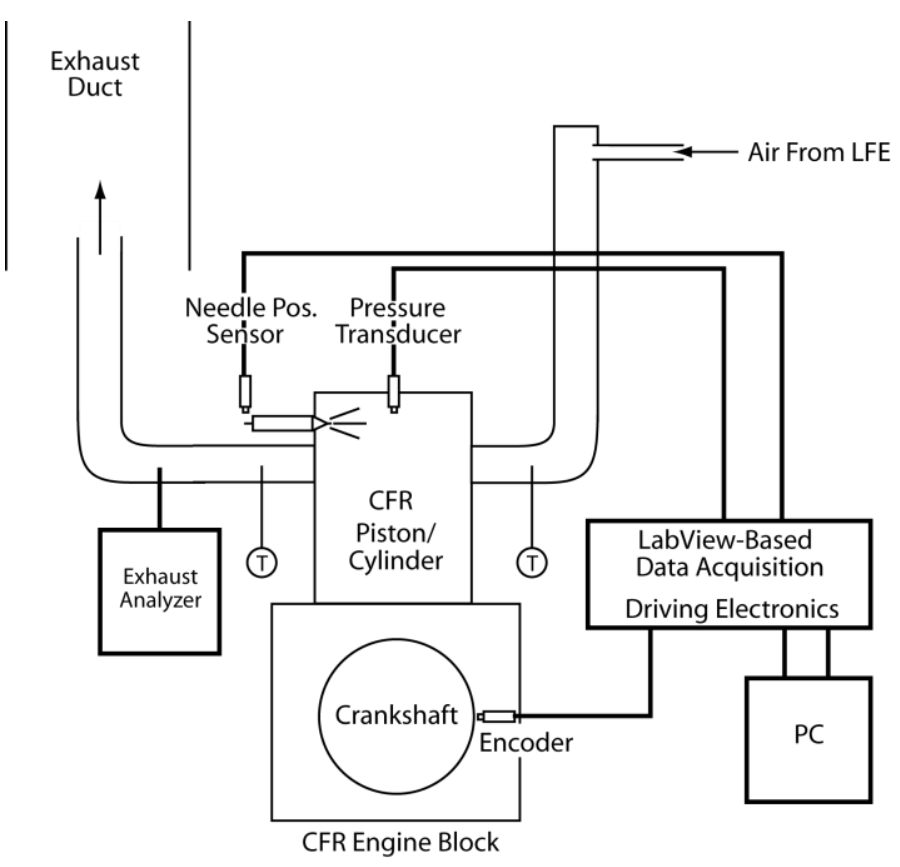

Figure 1: Schematic of experimental diesel CFR engine.

Exhaust gas was analyzed using a steady-state analyzer system and sampled from the exhaust flow using a heated filter approximately $10 \mathrm{~cm}$ downstream of the combustion chamber using a five-gas Infrared Industries ${ }^{\mathrm{TM}}$ FGA4000XD exhaust gas analyzer. Hydrocarbons $(\mathrm{HC})$, carbon dioxide $\left(\mathrm{CO}_{2}\right)$, carbon monoxide $(\mathrm{CO})$ were measured using a non-dispersive infrared process while oxygen $\left(\mathrm{O}_{2}\right)$ and nitric oxide (NO) were measured using an electrochemical cell method. Exhaust gas was sampled on a dry basis through a non-heated line; only NO emissions data are reported in this study.

\section{Engine Testing}

The diesel CFR engine is designed for testing fuels. In its stock configuration, it utilizes a rotary valve to switch between a system of three small fuel tanks. In this study, the binary mixture of toluene-hexadecane was added to the first fuel tank. Testing a particular mixture began with a flushing procedure as follows: First, a small amount of the fuel blend of interest was added to the first fuel tank and combustion was stabilized with this fuel blend. Then, the tank, injection pump, fuel metering burette, and associated lines were drained. Once the engine stopped firing, all of the fuel lines were emptied of the fuel blend. This procedure was repeated a second time, with a second drainage step. Finally, approximately $0.5-0.75 \mathrm{~L}$ of the fuel blend of interest was added to the first tank and to the fuel burette. The fuel was metered by direct volume measurement over approximately 60 seconds of engine operation using the fuel burette. Prior to data collection, the engine was operated with the fuel blend until steady operation was achieved.

Testing began by adjusting fuel delivery to achieve $3.5 \pm$ 0.05 bar gross indicated mean effective pressure (GMEP) at the lowest (most retarded) possible injection timing setting for the engine. Typically, this resulted in start of injection (SOI) timing around $13^{\circ}$ before top-center (BTC). The GMEP and SOI were determined by averaging 40 engine cycles using the data acquisition system described above. Five different injection advance settings were tested, typically achieving SOI between $13^{\circ}$ and $23^{\circ}$ BTC. As injection timing was adjusted, the fuel delivery was adjusted simultaneously to maintain 3.5 bar GMEP. In this study, operating points were grouped together as "retarded" with injection timing $13^{\circ} \pm 0.5^{\circ} \mathrm{BTC}$, "nominal" with injection timing $15^{\circ} \pm 0.5^{\circ} \mathrm{BTC}$, and "advanced" with injection timing $20^{\circ} \pm 0.5^{\circ}$ BTC. In most cases, the "retarded" timing condition actually produced the lowest fuel consumption; the labels are only meant as descriptors relative to the adjustment range of the engine, and are not meant to suggest reference to best-torque timing. Due to limitations on the extent of fuel injection timing adjustment, optimized best-torque timing was not always possible to achieve with the various tested fuel blends. However, the injection timings shown in this study are representative of typical diesel injection timings. Once the desired load and injection timing were achieved, each operating point was maintained for several minutes to ensure stable combustion and emissions measurements.

\section{Fuels and Binary Mixture Preparation}

Binary mixtures of toluene-n-hexadecane were prepared using a $1.0 \mathrm{~L}$ volumetric flask $( \pm 0.3 \mathrm{~mL}$ accuracy) and a $1.0 \mathrm{~L}$ graduated cylinder $( \pm 3.0 \mathrm{~mL}$ accuracy $)$. Combining the accuracy of all volume measurements, the largest expected error is $\pm 0.2 \%$ on the cited concentration (e.g. $70 \% \pm 0.2 \%$ ).

Hexadecane was acquired from Sigma-Aldrich ${ }^{\mathrm{TM}}$ with specified purity > 99\%. The toluene was acquired from Chevron Phillips $^{\mathrm{TM}}$ with a specified purity of $99.5 \%$ minimum. A comprehensive listing of the pure component fuels and fuel blends tested is shown in the Appendix. Two conventional fuels (commercial diesel and U.S. Navy JP-5, neat) and five synthetic fuels (neat) were included for comparison with the simple binary mixtures.

Cetane number was determined for all tested fuels using a variety of methods. By definition, pure hexadecane has a cetane 
number of 100 . For $50 \%$ and $80 \%$ blends of toluene with hexadecane, cetane number was measured in-house using the diesel CFR test engine and the ASTM D613 test specification with hexadecane and heptamethylnonane as primary reference fuels [11]. The cetane number for toluene was used as cited in Ref. [12]. There is disagreement over the cetane number of toluene, with cited values ranging from -5 to 18.3 . In this study, the literature value of -5 (from Ref. [13]) is adopted as it agrees very well with the measured cetane number of the toluene blends. Finally, measurements of the cetane number and lower heating value of the commercial diesel, JP-5, and the five synthetic blends were provided by the Fuels Division of the Naval Air Systems Command using the ASTM D976 and ASTM D4809 testing specification [14] and [15]. The lower heating value for pure components and binary mixtures was calculated based on published enthalpy of formation data [16].

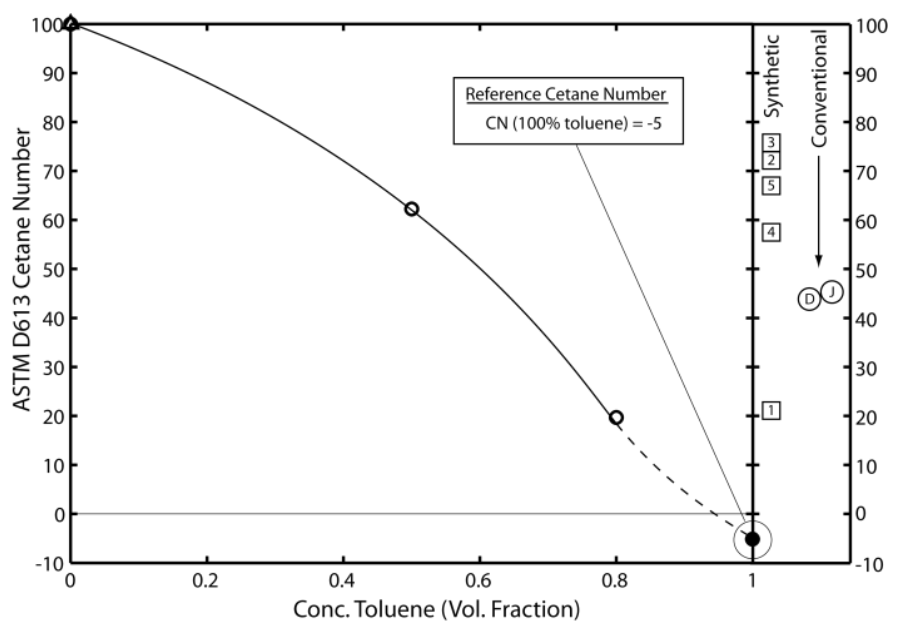

Figure 2: Cetane number vs. concentration of toluene $\left(\mathrm{C}_{7} \mathrm{H}_{8}\right)$ with $\mathrm{n}$-hexadecane $\left(\mathrm{C}_{16} \mathrm{H}_{34}\right)$. Toluene-hexadecane blends at $50 \%$ and $80 \%$ were measured using the ASTM D613 test [11]. The solid data markers represent published cetane values for pure toluene. On the right, five different synthetic fuels and conventional diesel and jet fuel are also shown.

Properties for these binary mixtures, as well as for the conventional and synthetic fuels described in this study were previously described in detail in Reference [10] and are shown in the Appendix. In addition to cetane number, the appendix includes the liquid-air surface tension, liquid kinematic viscosity, liquid density, and associated accuracy specifications. Distillation profiles were not measured in this study, but are also of interest for assessing the effect of fuel property changes on combustion characteristics. Atmospheric boiling point temperatures for n-hexadecane and toluene are $281^{\circ} \mathrm{C}$ and $111^{\circ} \mathrm{C}$ (data from Ref. [16]).

\section{Energy Release Analysis}

A single zone heat release analysis was used in this study [17], [18] and [19]. This analysis is useful to characterize start of combustion and burn durations. Start of injection (SOI) was determined from an injector position sensor. Start of combustion (SOC) was determined analytically as the $10 \%$ fuel burned state. Ignition delay was then determined analytically as the difference between SOI and SOC. The 50\% mass fraction burned location (CAD50) is used as an indicator of combustion phasing.

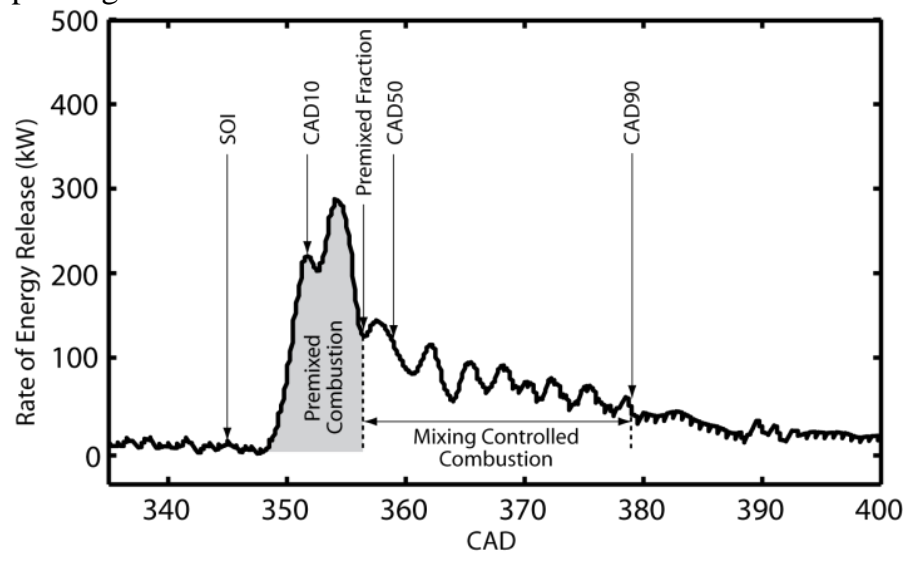

Figure 3: Typical rate of energy release profile (single cycle). The start of injection (SOI); $10 \%, 50 \%$, and $90 \%$ mass fraction burned locations (CAD10, CAD50, CAD90); and the estimated location of the premixed combustion phase are shown on the figure.

\section{IGNITION DELAY MODELING}

\section{Physical Delay Period}

A conceptual model of the ignition delay period, similar to that proposed in Ref. [1], is shown in Figure 4. The physical delay portion $\left(\tau_{\text {phys }}\right)$ of this model includes the time required for a fuel spray to leave the injector, form droplets and entrain hot air, vaporize, mix, and reach a critical temperature required for the onset of rapid chemical reaction. These steps may all be occurring simultaneously and are depicted, along with associated fuel properties, in Figure 4. The chemical delay period $\left(\tau_{\text {chem }}\right)$ includes the time required to initiate the chemical reactions that will quickly lead to explosive chain branching. Some associated fuel chemical properties are also shown in Figure 4. In the forthcoming analysis the physical delay period will be determined as the difference between empirical total ignition delay $\left(\tau_{\text {ign }}\right)$ and the model predicted chemical ignition delay $\left(\tau_{\text {chem }}\right)$, to be described next. 


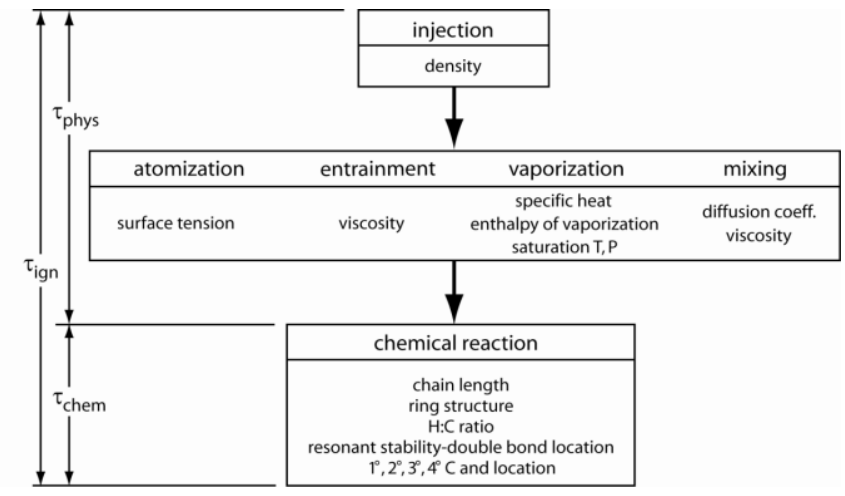

Figure 4: Conceptual model of ignition delay showing both the physical and chemical delay period, the processes that occur in each, and some fuel properties that affect to each of these processes.

\section{Chemical Delay Period}

Once a fuel-vapor and air mixture is obtained with suitable temperature and mixture ratio for chemical reaction, there is a chemical delay period during which chemical reaction rates increase, ultimately leading to significant fuel chain branching. At high temperatures the main chain branching reactions involve $\mathrm{H}$ radicals reacting with molecular oxygen to form $\mathrm{OH}$ plus $\mathrm{O}$; when the temperature is lower though, the chemistry of hydroperoxides is dominating and around $900 \mathrm{~K}$ the main source of radicals is the rapid decomposition of $\mathrm{H}_{2} \mathrm{O}_{2}$ into two $\mathrm{OH}$ radicals. Although the addition of alkyl radicals $(\mathrm{R})$ to molecular oxygen $\left(\mathrm{O}_{2}\right)$ occurs at a slightly lower temperature, it also leads to degenerate chain branching and is extremely important to predict the onset of ignition in low- and moderatetemperature combustion systems such as diesel combustion [20]. Low temperature chain branching occurs in a several step process involving an alkylperoxy $\left(\mathrm{RO}_{2}\right)$ isomerization step, in which a peroxy group abstracts an $\mathrm{H}$ from the chain through a ringed transition state:

$$
\mathrm{RO}_{2} \rightarrow \mathrm{QOOH}
$$

The rate of this isomerization step depends on the size of the ringed transition state and the type of $\mathrm{C}-\mathrm{H}$ which is broken by the abstraction. For long chain alkane species, there are many possible routes for this isomerization step, and thus the overall rate is faster than for shorter chain length species. The time required for these steps to yield significant chain branching is the main component of the chemical delay.

In order to more completely address the split between physical and chemical delay period, the chemical delay period was modeled using computer simulation using an approach similar to others found in Refs. [21] and [22]. Ignition delay was modeled as a homogeneous constant pressure reactor using a wide range of equivalence ratio (2-10) in order to evaluate ignition delay effects across a broad range of fuel-air mixtures.
Initial conditions were chosen at $770 \mathrm{~K}$ and 55 bar, the latter indicative of cylinder pressure at top center prior to chemical reaction in the combustion chamber and indicative of the environment into which fuel is injected in the experimental engine used in this study.

Detailed chemical kinetic mechanisms were used for both $\mathrm{n}$-hexadecane and toluene in order to compare the simulations to the experimental results. The chemical kinetic model for $\mathrm{n}$ hexadecane and toluene was assembled by combining a previously developed mechanism for large $n$-alkanes and a mechanism for toluene. The mechanism for large n-alkanes considers n-alkanes up to n-hexadecane [22]. It includes both low and high temperature chemistry so that it can simulate ignition over the entire temperature range for diesel combustion. It has been validated for ignition over a wide range of temperatures, pressures and equivalence ratios. The toluene mechanism was recently developed by Mehl et al. [23]. It also has been validated for ignition over a wide range of temperature, pressure and equivalence ratios relevant to diesel engines. To create the present mechanism, the species and reactions necessary to model the $\mathrm{C} 8$ to $\mathrm{C} 16$ n-alkanes [22] were added to the toluene, n-heptane, iso-octane mechanism described in [20].

\section{RESULTS AND DISCUSSION}

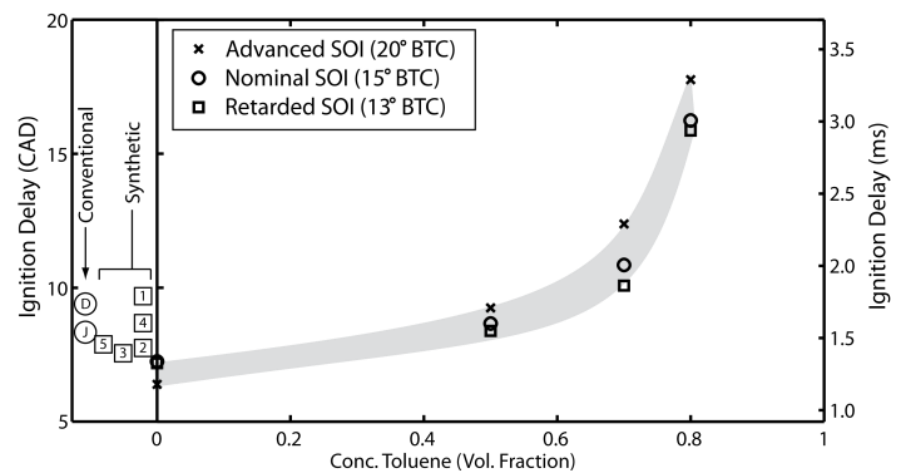

Figure 5: Ignition delay as a function of toluene $\left(\mathrm{C}_{7} \mathrm{H}_{8}\right)$ volume fraction with hexadecane $\left(\mathrm{C}_{16} \mathrm{H}_{34}\right)$. Three different injection timings are shown for each blend corresponding to advanced ( 20BTC), nominal ( 15\%BTC), and retarded ( 13B. synthetic fuels and conventional diesel and jet fuel are also shown at nominal ( 15BTC) SOI.

The key experimental ignition delay summary figure from this study is shown in Figure 5. Ignition delay in both engine crank angle degrees (left side) and ignition delay in milliseconds (right side) are shown as a function of toluene fraction. For a zero toluene fraction (pure n-hexadecane) the ignition delay is the shortest, while for high toluene concentrations ignition delay is much longer (moving right along the data). For practical hydrocarbons, the authors have shown that $\mathrm{n}$-hexadecane has the quickest (shortest) ignition delay, in this case nominally $1.25 \mathrm{msec}$. It can be seen that 
injection timing is particularly insensitive due to the short ignition delay.

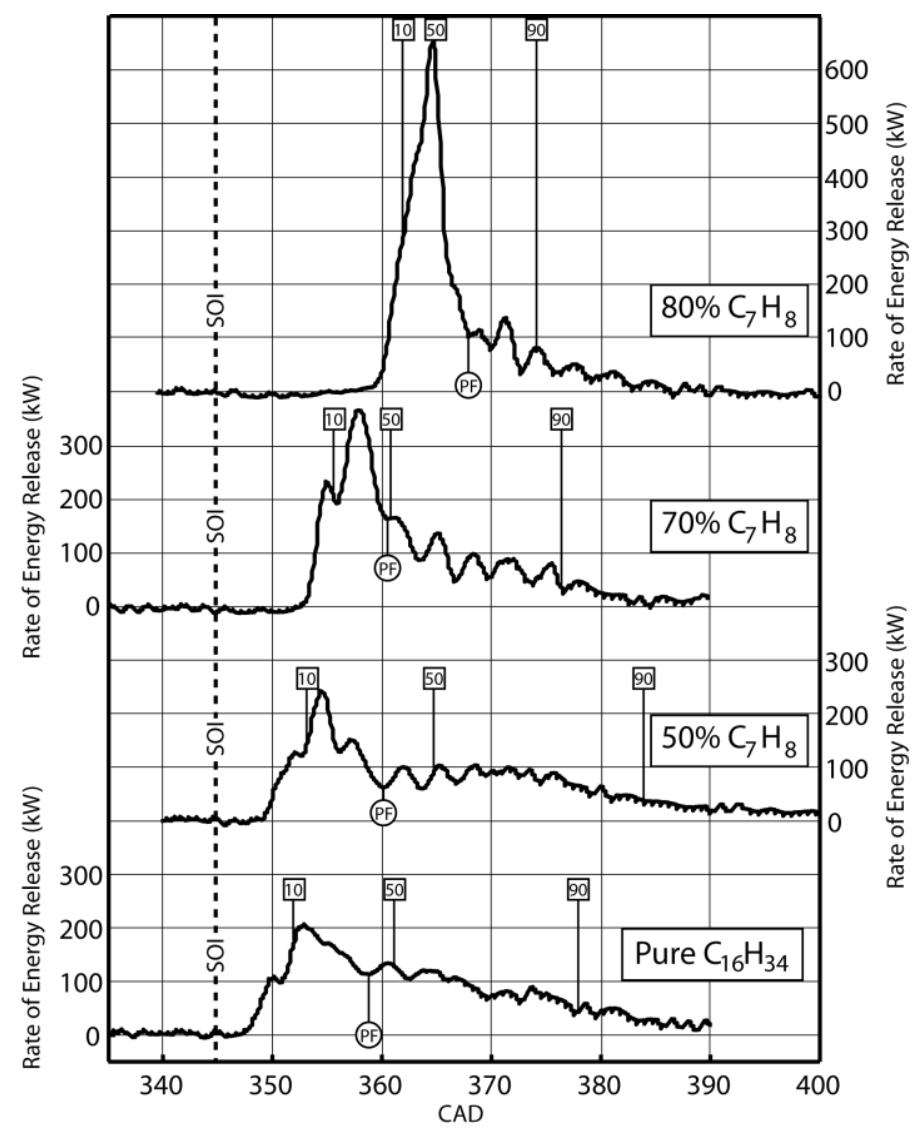

Figure 6: Rate of energy release (single cycles) for blends of toluene $\left(\mathrm{C}_{7} \mathrm{H}_{8}\right)$ with hexadecane $\left(\mathrm{C}_{16} \mathrm{H}_{34}\right)$ at nominal soi ( 15BTC). Each cycle was chosen to be representative of the average. The $10 \%, 50 \%$, and $90 \%$ mass fraction burned points are indicated, as well as the estimated end of the premixed combustion phase (PF).

A reference box is at the left side of this figure showing some common and alternative fuels. These results were from previous studies by the authors [10],[24]. Diesel fuel (\#2, "D") and jet fuel (JP-5, "J") are the two common fuels used by the US Navy in diesel engines. In this CFR engine at this mid-load point the ignition delay is nominally 1.5 to 1.75 milliseconds, approximately $25 \%$ longer than n-hexadecane. The fuels listed by numbers in the reference box are FT fuels, which tend to have higher cetane numbers than conventional fuels and thus shorter ignition delays in the case of FT fuels 2, 3 and 5.

The overall trend in the ignition delay data is that increasing the fraction of toluene has only a modest effect on ignition delay up to approximately $50 \%$ toluene. Increasing toluene fractions beyond 50\% markedly lengthens ignition delay. The engine was not able to run on $85 \%$ toluene. With $75 \%$ toluene the ignition delay time has doubled. The current Navy diesel fuel and jet fuel specifications list a maximum aromatic content at $25 \%$. From the practical perspective, the insensitivity to toluene fraction below $50 \%$ is notable, as using toluene as an additive to HVO-HRD and FT fuels (with essentially zero aromatic content) up to $25 \%$ appears to have only a very modest effect.

Detailed instantaneous heat release analysis results are shown for four toluene blends in Figure 6. Moving upwards in the figure corresponds to increasing toluene fraction. The Start of Injection (SOI) is the same for all four cases, fixed at $15^{\circ}$ BTC. The ten percent burn location (CAD10) is at the "10" box label along each instantaneous heat release data curve. The ignition delay is the crank angle difference from the SOI to CAD10. The increase in ignition delay is evident as toluene fraction increases up to $80 \%$. Coupled with the long ignition delay for this $80 \%$ toluene case is a rapid heat release. This is due to the significant pre-mixing time associated with this low reactivity (low cetane) fuel, allowing for significant air to fuel mixing prior to ignition. Thus a greater quantity of fuel is prepared to burn upon ignition as compared to the nhexadecane case ( $0 \%$ toluene).

In looking at the mid-point of the combustion event (CAD50) in Figure 6 it is interesting that the CA50 shows a modest change, up to 4 crank angle degrees, with changing toluene fraction. Thus despite the longer ignition delay, the bulk combustion characteristics are not also delayed but actually faster due to the increased time for pre-mixing, thus the engine actually runs quite well.

Unfortunately, increasing the concentration of toluene from $80 \%$ to $85 \%$ resulted in a non-firing situation due to lack of ignition in the engine. Only a narrow window of time exists in the engine combustion chamber environment for the fuel to react. If the fuel-air reactions are too slow, the cylinder volume will increase as the piston falls, thus reducing the charge temperature, and further reducing the reactivity of the fuel. What is happening to the fuel (n-hexadecane and toluene) inside the combustion chamber as the toluene fraction increases? Does the hexadecane fraction still react, but is of such a low fraction that it cannot affect the bulk charge? Or are the hexadecane fuel reactions hindered by the significant toluene fraction? Companion modeling was pursued in order to aid in answering these fundamental questions, as well assist providing an analytical tool to predict the start of combustion in diesel engines.

The ignition delay modeling results using the chemical kinetic model are shown with the empirical results in Figure 7. The criterion for model predicted ignition delay will be discussed shortly. The modeling results are presented using solid and dashed trend lines for a range of representative fuelair packets resulting from the diesel injection spray, while the experimental data points are shown in a shaded band with three different symbols for each SOI. For both the experimental data and modeling results the ignition delay increases monotonically with increasing toluene fraction. It should be noted that no model calibration was pursued in this study, thus the general agreement in trends of increasing ignition delay with increasing toluene fraction is excellent. 


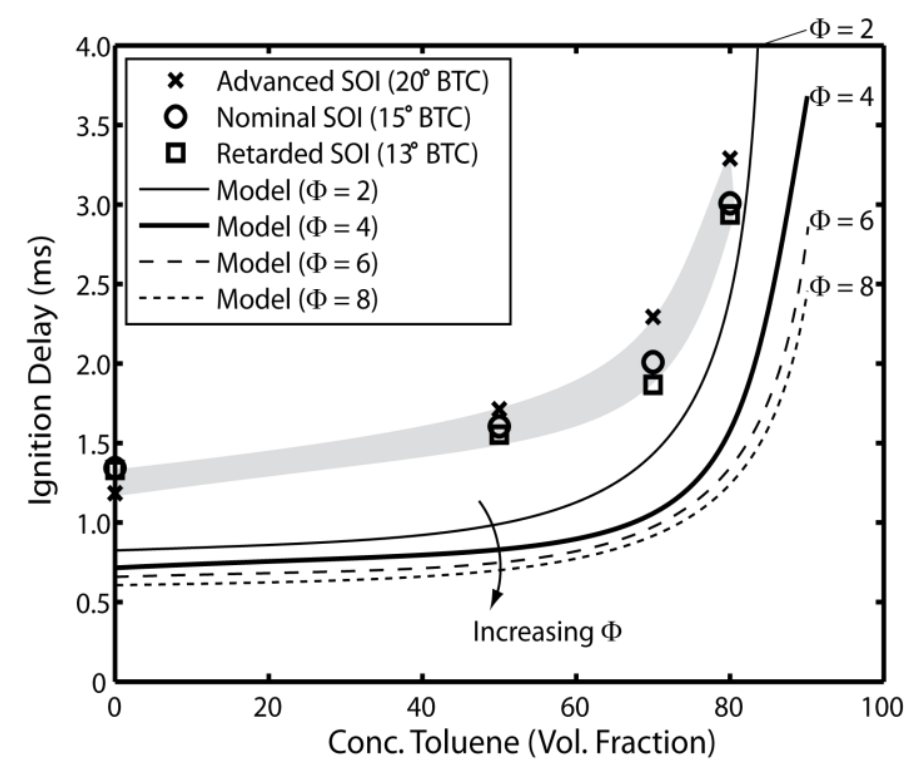

Figure 7: Ignition delay vs. Volumetric percentage of toluene $\left(\mathrm{C}_{7} \mathrm{H}_{8}\right)$ in a binary mixture with Hexadecane $\left(\mathrm{C}_{16} \mathrm{H}_{34}\right)$. The data points in the shaded band correspond to experimentally measured ignition delays. The solid and dashed trend lines are chemical kinetic modeling under these corresponding to fuel-air equivalence ratios from 2 to 8 (55 bar and $770 \mathrm{~K}$ ).

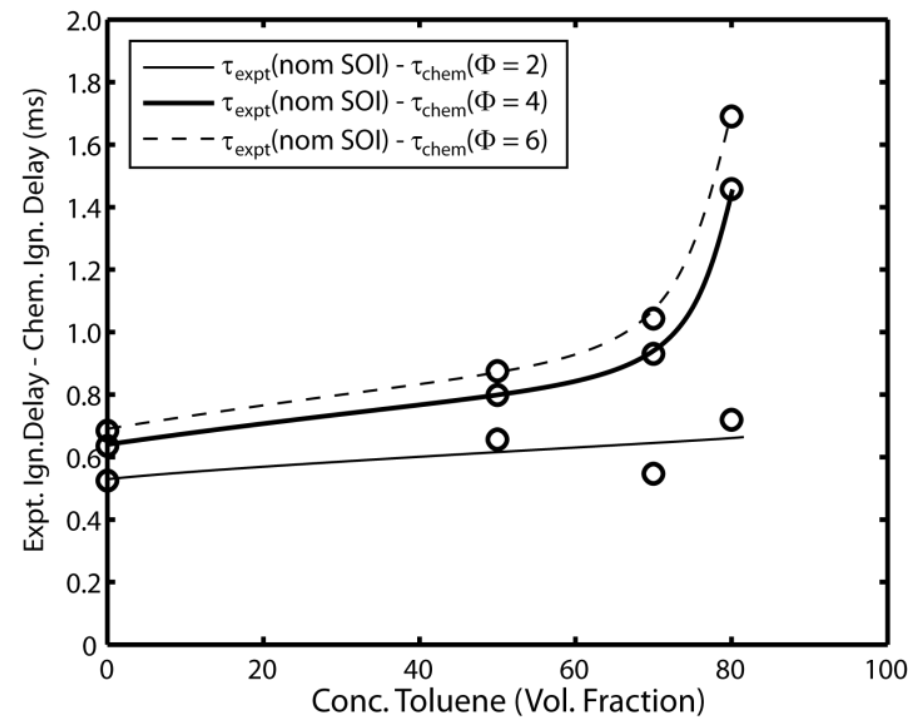

Figure 8: Physical ignition delay vs. Volumetric percentage of toluene $\left(\mathrm{C}_{7} \mathrm{H}_{8}\right)$ in a binary mixture with hexadecane $\left(\mathrm{C}_{16} \mathrm{H}_{34}\right)$. Chemical ignition delays from chemical kinetic modeling were subtracted from the experimentally measured ignition delay in the research engine to show the physical ignition delay associated with that blend.
The difference between the experimental and model predicted ignition delay results are shown in Figure 8. It is important to recall that the ignition delay "clock" for the model simulations starts assuming that representative packets of wellmixed fuel and air already exist ( $\phi$ from 2 to 10). Thus, the analytical ignition delay represents a pure chemical ignition delay $\left(\tau_{\text {chem }}\right)$ as outlined in the conceptual ignition delay structure of Figure 4. The experimental ignition delay includes both the physical and chemical ignition delay effects. Thus the difference between the experimental and analytical results represents the physical delay time in the actual engine environment. Figure 8 shows that the physical ignition delay time increases with toluene fraction just as the chemical ignition delay. The increase in ignition delay with increasing equivalence ratio is likely due to the increased importance of charge cooling. Raw data are shown in Table 2; the physical delay increases by nearly $50 \%$ (relative) between the pure hexadecane and the $70 \%$ toluene blend; the $80 \%$ toluene blend causes approximately a $130 \%$ relative increase in this physical ignition delay time. On a relative basis, the chemical and physical ignition delay increase equally as the fraction of toluene increases. Note, again, that this physical delay period is the observed, total ignition delay with the chemical ignition delay (as predicted by the kinetic model) removed.

Table 2 also shows the relative changes in bulk mixture properties, including the molecular weight, liquid-air surface tension, kinematic viscosity, density, cetane number, and energy content (LHV). Some of these, in particular the first four, would be expected to have some effect on the physical mixing processes in the diesel fuel spray. Note that of these four, only the molecular weight and viscosity show substantial relative changes (54\% and $81 \%$, respectively) between $0 \%$ and $80 \%$ toluene blends (shown in bold in the table). Boiling point (or a metric such as the $50 \%$ distillation temperature) is not shown but is expected to scale closely with molecular weight.

In addition to some differences in physical properties, the chemical kinetics of aromatics are very different as compared to normal alkanes (e.g. n-hexadecane). A graph of ignition delay modeling results as a function of toluene fraction is shown in Figure 9 plotted against inverse temperature $(1 / \mathrm{T})$. These simulation results were all at 55 bar, using the constant pressure reactor simulation approach described earlier. This analytical presentation is a more common presentation of kinetic simulations, and due to the inverse temperature abscissa, lower temperatures are to the right in the figure. The model results shown in this paper assume an ignition temperature of $770 \mathrm{~K}$ after previous models in the literature ([23], [25]-[27]). This temperature corresponds to $1.3(1000 / \mathrm{T})$ in Figure 9. Chemical ignition delay is relatively insensitive to temperature in this temperature regime, although the initial toluene fraction does have a significant effect on predicted ignition delay. For higher initial toluene fraction, chemical ignition delay is always longer at any given temperature. As temperature increases, the ignition delay is predicted to be shorter as the fuel-air mixtures react more quickly. 
Table 2: Ignition delay and bulk property data for pure hexadecane, toluene, and 50,70 , and $80 \%$ toluene in hexadecane blends. The right-most columns show these data as relative changes, normalized to the values of pure hexadecane $(0 \%$ toluene).

\begin{tabular}{|c|c|c|c|c|c|c|c|c|c|}
\hline \multicolumn{6}{|c|}{ Raw Property and Performance Data } & \multicolumn{4}{|c|}{ Changes Relative to Pure $\mathrm{C}_{16} \mathrm{H}_{34}$} \\
\hline Vol. Frac. Toluene & $0 \%$ & $50 \%$ & $70 \%$ & $80 \%$ & $100 \%$ & $0 \%$ & $50 \%$ & $70 \%$ & $80 \%$ \\
\hline Ign. Del. (ms) & 1.34 & 1.60 & 2.01 & 3.01 & $\mathrm{~N} / \mathrm{A}$ & 0 & 0.19 & 0.50 & 1.25 \\
\hline Chem. Ign. Del. (ms) & 0.707 & 0.806 & 1.08 & 1.55 & $N / A$ & 0 & 0.14 & 0.53 & 1.19 \\
\hline Phys. Ign. Del. (ms) & 0.60 & 0.75 & 0.95 & 1.50 & $\mathrm{~N} / \mathrm{A}$ & 0 & 0.25 & 0.47 & 1.31 \\
\hline MW (kg/kmol) & 226.0 & 127.7 & 110.1 & 103.2 & 92.0 & 0 & -0.43 & -0.51 & -0.54 \\
\hline$\sigma(\mathrm{mN} / \mathrm{m})$ & 26.3 & 26.6 & 27.1 & 27.4 & 27.9 & 0 & 0.01 & 0.03 & 0.04 \\
\hline $\mathrm{v}\left(\mathrm{mm}^{2} / \mathrm{s}\right)$ & 4.47 & 1.31 & 0.95 & 0.83 & 0.66 & 0 & -0.71 & -0.79 & -0.81 \\
\hline$\rho\left(\mathrm{kg} / \mathrm{m}^{3}\right)$ & 774 & 817 & 836 & 846 & 867 & 0 & 0.06 & 0.08 & 0.09 \\
\hline cetane number & 100 & 62.3 & 33.9 & 19.7 & -5 & 0 & -0.38 & -0.66 & -0.80 \\
\hline LHV (MJ/kg) & 43.9 & 42.3 & 41.6 & 41.3 & 40.5 & 0 & -0.04 & -0.05 & -0.06 \\
\hline
\end{tabular}

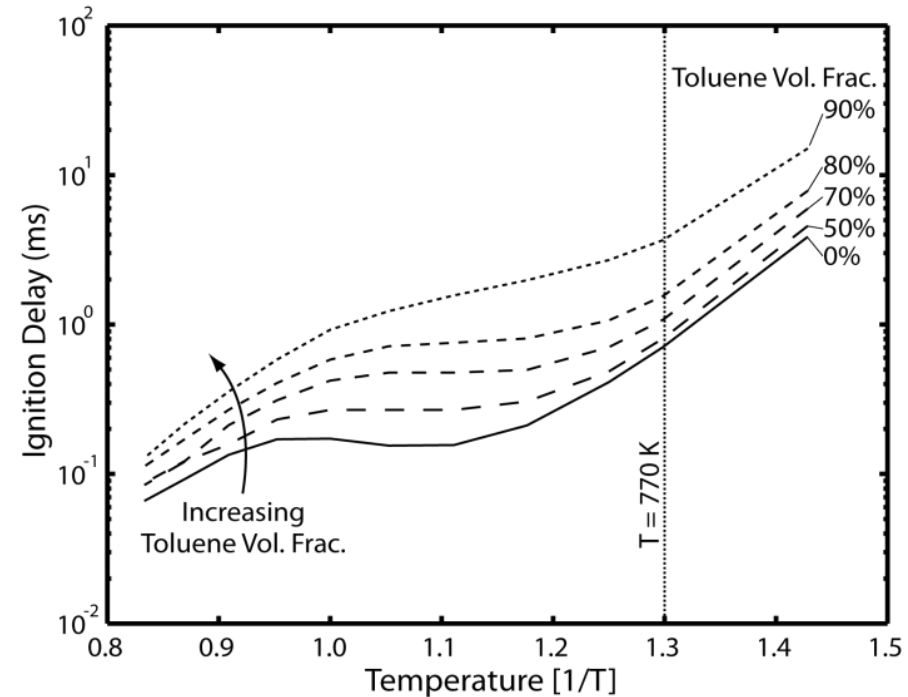

Figure 9: Chemical kinetic modeling of ignition delays as a function of temperature with volumetric percentage of toluene $\left(\mathrm{C}_{7} \mathrm{H}_{8}\right)$ in a binary mixture with hexadecane $\left(\mathrm{C}_{16} \mathrm{H}_{34}\right)$ increasing from bottom to top, fuel-air equivalence ratio of 4.

The temperature range in the central part of Figure 9 shows some interesting trends. This Negative Temperature Coefficient
(NTC) region is from approximately 1 to $1.2(1000 / \mathrm{T})$. In this region, for all but the highest concentration of toluene, the ignition delay is insensitive to the chamber temperature. This region has been shown to be important for straight chain alkanes where endothermic reactions delay kinetics. In this temperature regime (approximately $850 \mathrm{~K}$ ), alkylperoxy fuel radicals $\left(\mathrm{RO}_{2}\right)$ become unstable preventing the low temperature degenerate chain branching to take place, leaving the hydroperoxyl radical $\left(\mathrm{HO}_{2}\right)$ and hydrogen peroxide $\left(\mathrm{H}_{2} \mathrm{O}_{2}\right)$ decomposition to control the reactivity [28]. At lower temperatures, characteristic of the end of compression combustion chamber environment, the dominant kinetic paths takes place primarily through the formation of alkyl-peroxy radicals $\left(\mathrm{RO}_{2}\right)$ via addition of molecular oxygen to alkyl $(\mathrm{R})$ radicals, followed by production of alkyl hydroperoxides (QOOH).

The chemical kinetic model provides detailed insights into these early reactions leading to combustion. Figure 10 shows the formation of the hydroperoxy radical $\left(\mathrm{HO}_{2}\right)$. This radical can be formed by the concerted elimination reaction $(\mathrm{ROO} \rightarrow$ Olefin $+\mathrm{HO} 2)$ or by the addition of $\mathrm{O}_{2}$ to a hydrogen atom that was recently eliminated by partially oxidized fuel fragments. It is very interesting that while the $50 \%$ toluene blend ignites later than the pure n-hexadecane fuel $(0 \%$ toluene), $\mathrm{HO}_{2}$ formation is stronger for the 50-50 blend during 
the first $0.75 \mathrm{msec}$ after reactions begin. The reason for this is that the hydrogens on the methyl group of toluene are weakly bound because of the resonant stabilization of the benzyl radical, leading to easier hydrogen abstraction from the fuel molecule. However, toluene has only one methyl group so this hydrogen source is limited during the initiation phase of the kinetics. The hydrogen abstraction reactions from the $\mathrm{n}$ hexadecane (many more primary and secondary $\mathrm{H}-\mathrm{C}$ bonds than toluene) finally surpass that of the toluene leading to combustion at $0.7 \mathrm{~ms}$.

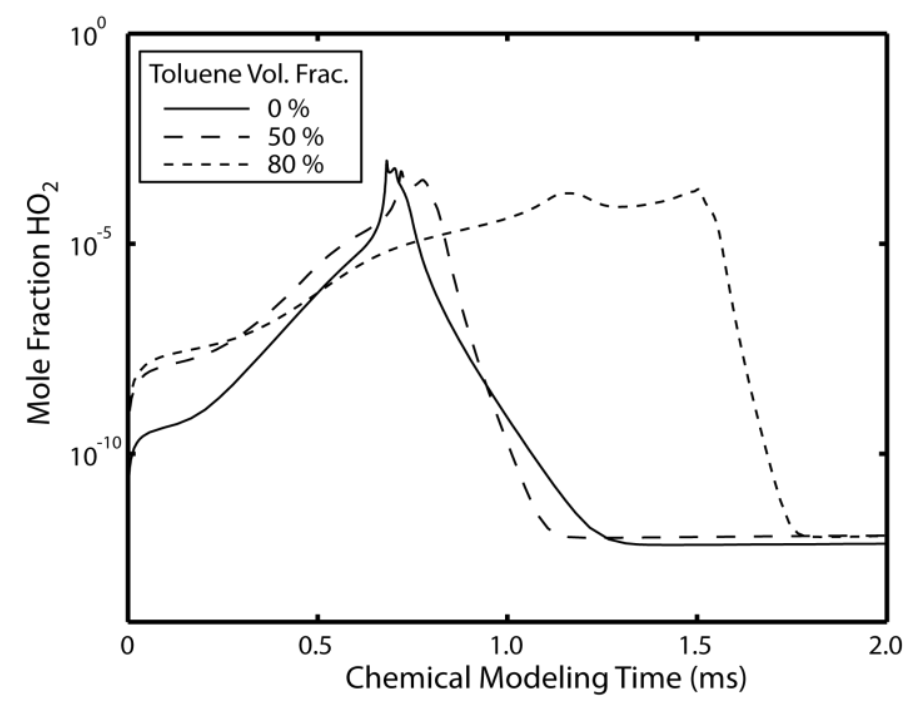

Figure 10: $\mathrm{HO}_{2}$ (hydroperoxy) radical production for 0,50 , and $80 \%$ toluene in hexadecane.

Hydrogen peroxide $\left(\mathrm{H}_{2} \mathrm{O}_{2}\right)$ formation is next shown in Figure 11 for 0,50 and $80 \%$ toluene. $\mathrm{H}_{2} \mathrm{O}_{2}$ is a strong oxidizer that can aid in further fuel decomposition. During the early phases of the kinetics, once the fuel vapor and air mixture have formed, $\mathrm{H}_{2} \mathrm{O}_{2}$ comes principally from reactions of fuel with $\mathrm{HO}_{2}$. Hydrogen peroxide also comes from the reaction of two $\mathrm{HO}_{2}$ molecules leading to $\mathrm{H}_{2} \mathrm{O}_{2}$ and $\mathrm{O}_{2}$. Interesting again, as in Figure 10, the $\mathrm{H}_{2} \mathrm{O}_{2}$ production for 50 and $80 \%$ toluene (in Figure 11) leads pure n-hexadecane early in the kinetics. However, the first fuel to combust is actually pure hexadecane ( $0 \%$ toluene) at $0.7 \mathrm{msec}$ due to the more plentiful $\mathrm{OH}$ radicals from this straight chain alkane once the chain branching reaction process develops. These radicals effectively attack the fuel chain, leading to a fast oxidation. When toluene is present in large amounts, the hydrogen atoms on the methyl group of toluene are also easily abstracted, but this forms the resonantly stabilized benzyl radical which is unreactive. The hydrogen atoms bound to the benzene ring of toluene are instead very strongly bound, thus toluene is slow to react at later times.

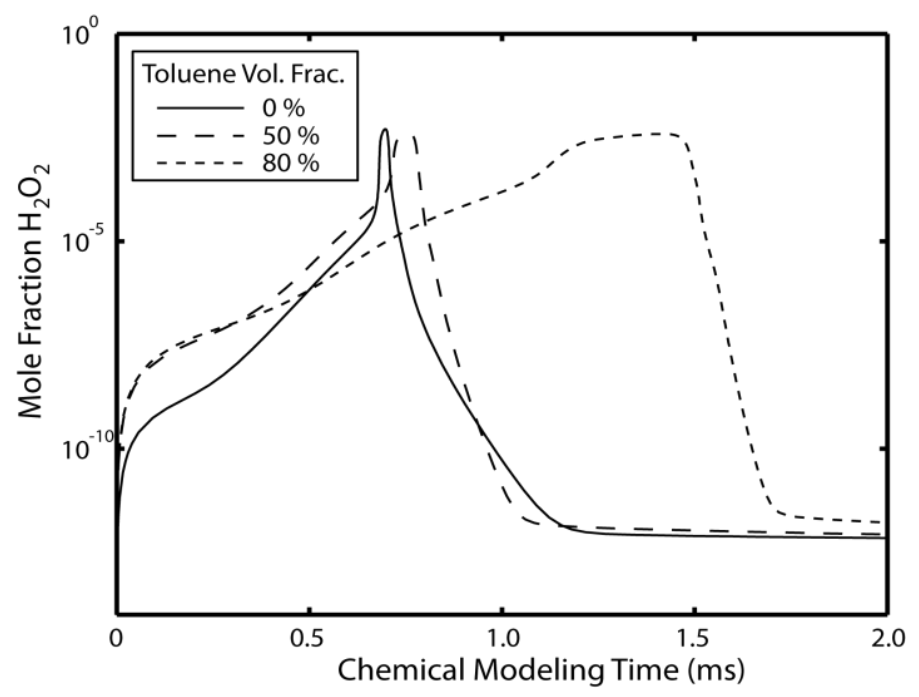

Figure 11: Hydrogen peroxide $\left(\mathrm{H}_{2} \mathrm{O}_{2}\right)$ formation for three surrogate blends.

While there are numerous species and quantitative approaches to define the time of ignition, using the electronically excited $\mathrm{CH}$ molecule, methylidyne, $\mathrm{CH}^{*}$ was chosen as an indicator for this study. Figure 12 shows $\mathrm{CH}^{*}$ concentrations as a function of time from the start of reaction for $0,50,70,80$ and $90 \%$ toluene. The peaks for $\mathrm{CH}^{*}$ were used to indicate the ignition onset in this study. It can be seen that for the high concentration toluene fuel, the ignition delay (the time period from the start of chemical activity to that of combustion) increases significantly.

$\mathrm{CH}$ principally comes from $\mathrm{C}_{2} \mathrm{H}_{2}$ after the fuel molecule has been broken down significantly:

$$
\begin{aligned}
& \mathrm{C}_{2} \mathrm{H}_{2}+\mathrm{O}=\mathrm{CH}_{2}+\mathrm{CO} \\
& \mathrm{CH}_{2}+\mathrm{H}=\mathrm{CH}+\mathrm{H}_{2}
\end{aligned}
$$

$\mathrm{CH}^{*}$ principally comes from $\mathrm{C}_{2} \mathrm{H}_{2}$ and hydroxyl radicals $(\mathrm{OH})$, which form more significantly as the chain branching associated with combustion occurs:

$$
\begin{aligned}
& \mathrm{C}_{2} \mathrm{H}_{2}+\mathrm{OH}=\mathrm{C}_{2} \mathrm{H}+\mathrm{H}_{2} \mathrm{O} \\
& \mathrm{C}_{2}+\mathrm{OH}=\mathrm{CO}+\mathrm{CH}^{*} \\
& \mathrm{C}_{2} \mathrm{H}+\mathrm{O}=\mathrm{CO}+\mathrm{CH}^{*}
\end{aligned}
$$$$
\mathrm{C}_{2} \mathrm{H}+\mathrm{O}_{2}=\mathrm{CO}_{2}+\mathrm{CH}^{*}
$$ 


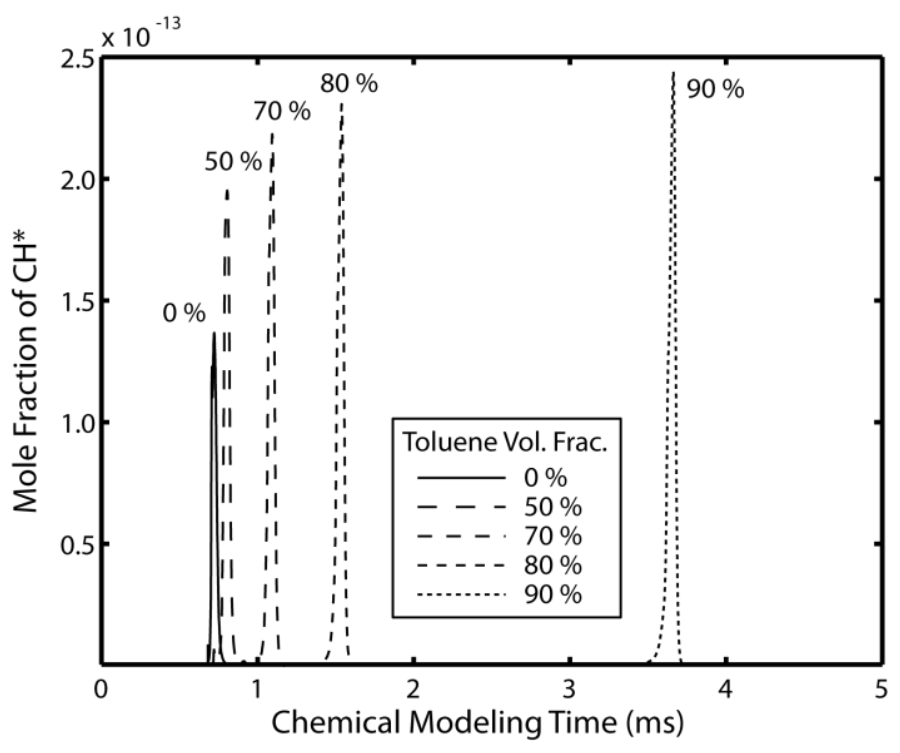

Figure 12: Mole fraction of $\mathrm{CH}^{*}$ as a function of time with volumetric percentage of toluene $\left(\mathrm{C}_{7} \mathrm{H}_{8}\right)$ in a binary mixture with hexadecane $\left(\mathrm{C}_{16} \mathrm{H}_{34}\right)$ increasing from left to right.

The overall fuel to products $\left(\mathrm{CO}\right.$ and $\left.\mathrm{CO}_{2}\right)$ kinetic summary is shown in Figure 13 for 0,50 and 80 percent toluene. The topmost graph in the figure shows n-hexadecane ( $0 \%$ toluene) as the solid curve. At nominally $0.7 \mathrm{msec}$ the fuel concentration quickly drops as the fuel molecule is breaking up. Corresponding to this rapid fall in fuel concentration is also a rapid rise in $\mathrm{CO}$ followed by the final combustion product $\mathrm{CO}_{2}$. Many of the reactions that form both $\mathrm{CO}$ and $\mathrm{CO}_{2}$ are highly exothermic which leads to the high temperature reactions characteristic of combustion.

The middle figure shows the reaction summary for the 5050 blend. It can be seen that the $\mathrm{C}_{16}$ is the first of the two fuels to start reacting, as indicated by its falling concentration. In fact, the ignition time of nominally $0.75 \mathrm{~ms}$ for the $50-50$ blend is principally due to the combustion of n-hexadecane and not the toluene fraction as the model shows that toluene is consumed after the onset of combustion has occurred.

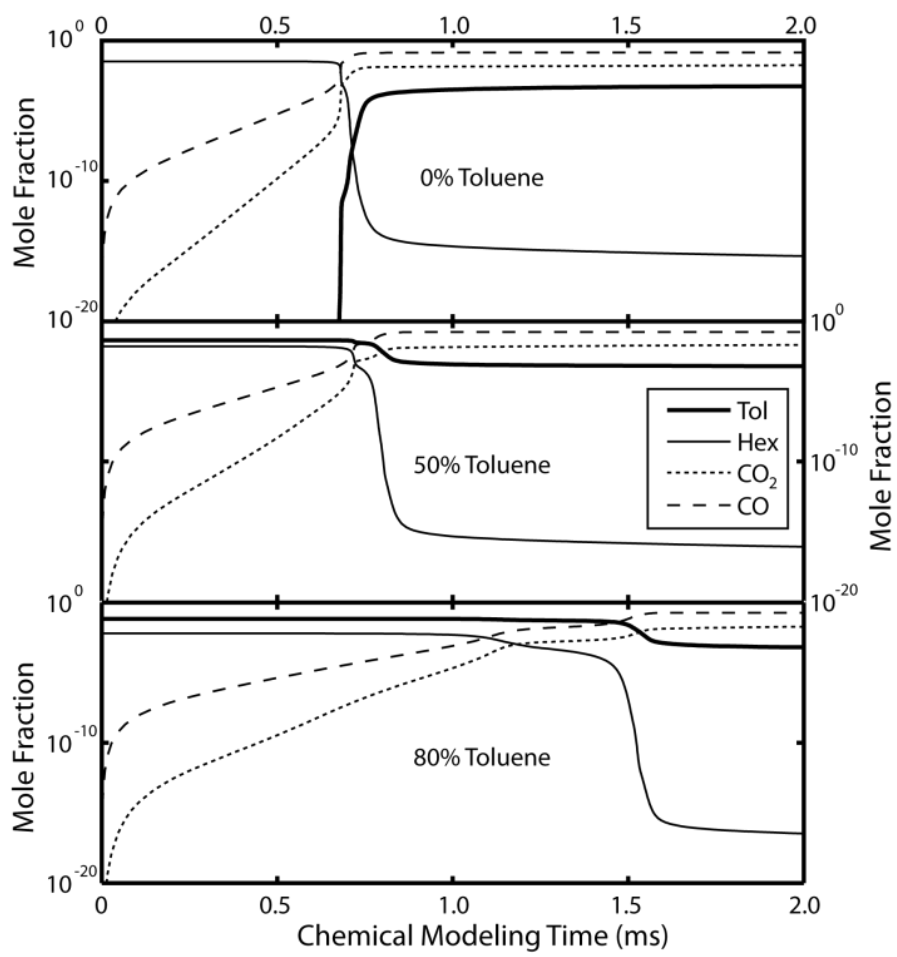

Figure 13: Model predicted concentrations of toluene $\left(\mathrm{C}_{7} \mathrm{H}_{8}\right)$, hexadecane $\left(\mathrm{C}_{16} \mathrm{H}_{34}\right), \mathrm{CO}_{2}$, and $\mathrm{CO}$ initially at $770 \mathrm{~K}$, 55 bar, fuel-air equivalence ratio 4 , and increasing initial volume fractions of toluene in hexadecane.

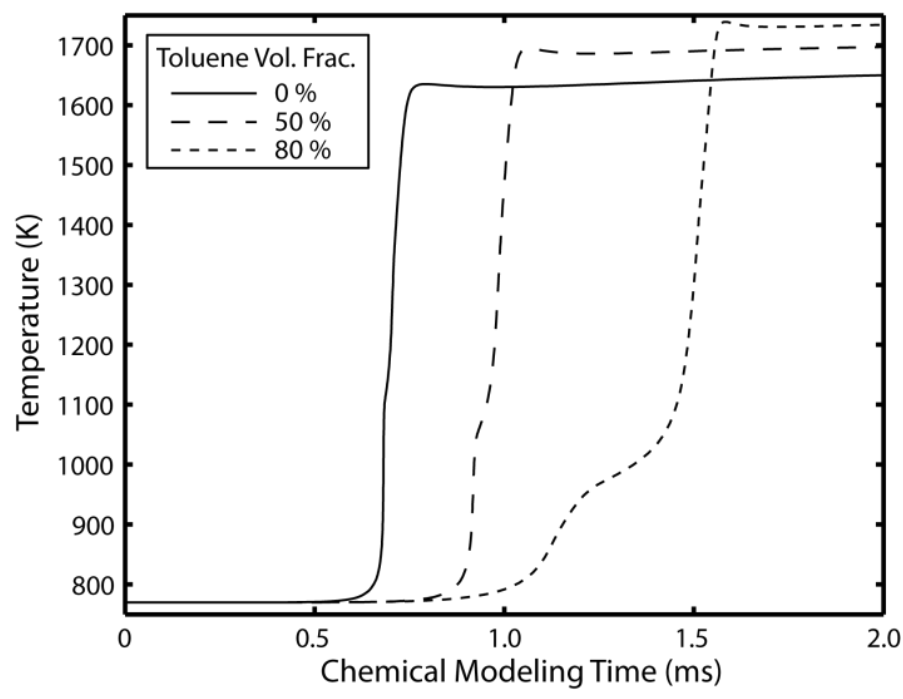

Figure 14: Temperature history of 0,50 , and $80 \%$ toluene in hexadecane mixtures as predicted by chemical kinetic modeling.

Likewise for the $80 \%$ toluene blend, the n-hexadecane starts to react at nominally $1 \mathrm{~ms}$ as seen by a reduction in $\mathrm{nC}_{16}$ concentration at this time. The rapid consumption in $\mathrm{nC}_{16}$ takes place at nominally $1.5 \mathrm{~ms}$ which is the onset of combustion as 
defined by the peak in $\mathrm{CH}^{*}$. The $\mathrm{nC}_{16}$ fuel decomposition takes place much later than in the case of pure $\mathrm{nC}_{16}$. This fact is due to the suppression of the nC16 chemistry by toluene. Toluene consumes $\mathrm{OH}$ radicals produced by $\mathrm{nC} 16$ oxidation and produces relatively unreactive benzyl radicals $\left(\mathrm{C}_{6} \mathrm{H}_{5} \mathrm{CH}_{2}\right)$. The high temperature reactions caused by the combustion of $\mathrm{nC}_{16}$ ultimately then cause the reaction of the toluene.

\section{SUMMARY/CONCLUSIONS}

Current alternative diesel fuels are often relatively simple mixtures of straight chain or simply branched paraffinic hydrocarbons and will likely require the addition of aromatic species for reasons such as ensuring adequate lubricity and proper elastomeric seal formation. The purpose of this study was to develop a better understanding of how aromatic species will affect such alternative fuels and also to build a framework by which possible future fuels could be evaluated for use in diesel engines. Experimental operation of normal hexadecane, a straight-chain paraffinic hydrocarbon $\left(\mathrm{C}_{16} \mathrm{H}_{34}\right)$, with varying fractions of toluene, an aromatic species $\left(\mathrm{C}_{7} \mathrm{H}_{8}\right)$, produced the following results:

- Diesel engine operation was possible up to $80 \%$ toluene. Ignition delay was only marginally affected with $50 \%$ toluene blends. Experimentally observed ignition delay increased from $1.34 \mathrm{~ms}$ (pure hexadecane) to $3.01 \mathrm{~ms}$ ( $80 \%$ toluene in hexadecane). Navy diesel fuel showed an ignition delay of $1.75 \mathrm{~ms}$, which corresponds to approximately a sixty percent toluene in hexadecane mixture.

- Analysis of energy release rates shows this increase in ignition delay. This experimental analysis also shows that the location of $50 \%$ mass fraction burned has a modest change with toluene fraction.

Chemical reaction rate modeling was conducted with a detailed chemistry model using a homogeneous, constant pressure reactor with defined initial temperature and pressure, at variable fuel-air equivalence ratios:

- The model predicts similar trends of ignition delay as observed in the actual engine, although, as expected, the predicted ignition delays are significantly lower than the observed values.

- The difference between the observed experimental ignition delay and the modeled homogenous chemical reactor ignition delay is defined as the physical ignition delay. Separating the observed ignition delay into a chemical and physical part shows that both parts contribute nearly equally to the total increase in ignition delay with the addition of toluene. Therefore, with addition of this aromatic species, both changes to chemical and physical delay have importance in predicting the overall ignition delay.

- Relative changes to bulk fuel properties show that, of the properties considered, only molecular weight and kinematic viscosity show large $(>10 \%)$ relative changes as toluene fraction is increased. Boiling point, or similar distillation profile metric, is expected to scale with molecular weight.

- Toluene actually produces a greater number of ignition precursors, such as $\mathrm{HO}_{2}$ and $\mathrm{H}_{2} \mathrm{O}_{2}$, sooner than hexadecane, due to the relatively weakly bound methyl group on the toluene ring. However, these precursors are insufficient to lead to ignition themselves. The presence of toluene inhibits hexadecane chemistry by consumption of $\mathrm{OH}$ radicals produced by hexadecane.

\section{CONTACT INFORMATION}

Jim Cowart: cowart@usna.edu

Patrick Caton: patcaton@usna.edu

\section{NOMENCLATURE}

$\begin{array}{ll}\text { ASTM } & \text { American Society of Testing and Materials } \\ \text { BTC } & \text { before top-center } \\ \text { CAD } & \text { crank angle degree } \\ \text { CAD10 } & \text { location of 10\% mass fraction burned } \\ \text { CAD50 } & \text { location of 50\% mass fraction burned } \\ \text { CAD90 } & \text { location of 90\% mass fraction burned } \\ \text { CFR } & \text { Cooperative Fuels Research } \\ \text { CKM } & \text { Chemical Kinetic Modeling } \\ \text { FT } & \text { Fischer-Tropsch } \\ \text { GMEP } & \text { gross indicated mean effective pressure } \\ \text { gISFC } & \text { indicated gross specific fuel consumption } \\ \text { HC } & \text { hydrocarbon } \\ \text { JP-5 } & \text { U.S. Navy designation for carrier-based jet } \\ \text { fuel } & \\ \text { NO } & \text { nitric oxide } \\ \text { PF } & \text { premixed fraction } \\ \text { SOC } & \text { start of combustion } \\ \text { SOI } & \text { start of injection } \\ \sigma & \text { liquid-air surface tension } \\ \rho & \text { liquid density } \\ v & \text { liquid kinematic viscosity }\end{array}$

\section{ACKNOWLEDGMENTS}

The authors wish to thank Dr. Dave Shiffler and Dr. Sharon Beerman-Curtain of the Office of Naval Research for their support of this work. The excellent technical support of $\mathrm{Mr}$. John Hein, Mr. Charles Baesch, and Mr. Bob Woody is also acknowledged. The portion of this work supported by LLNL was performed under the auspices of the U.S. Department of Energy by Lawrence Livermore national Laboratory under 
Contract DE-AC52-07NA27344. The portion of this work supported by LLNL was performed under the auspices of the U.S. Department of Energy by Lawrence Livermore National Laboratory under Contract DE-AC52-07NA27344.

\section{REFERENCES}

[1] Challen, B. and Baranescu, R., Diesel Engine Reference Book, SAE Publishing, 1999.

[2] Edward, T. "Kerosene Fuels for Aerospace Propulsion Composition and Properties," $38^{\text {th }}$ AIAA/ASME/SAE/ASEE Joint Propulsion Conference and Exhibit, Indianapolis, IN, July, 2002.

[3] Colket, M., Edwards, T., Williams, S., Cernansky, N., Miller, D., Egolfopoulos, F., Lindstedt, P., Seshadri, K., Dryer, F., Law, C., Friend, D., Lenhert, D., Pitsch, H., Sarofim, A., Smooke, M., Tsang, W. "Development of an Experimental Database and Kinetic Models for Surrogate Jet Fuels," 45 ${ }^{\text {th }}$ AIAA Aerospace Conference, 2007.

[4] Kuronen, M., Mikkonen, S., Aakko, P. And Murtonen, T., 'Hydrotreated Vegetable Oil as Fuel for Heavy Duty Diesel Engines', SAE Technical Paper \#2007-01-4031, 2007.

[5] Aatola, H., Larmi, M., Sarjovaara, T. and Mikkonen, S., , 'Hydrotreated Vegetable Oil (HVO) as a Renewable Diesel Fuel: Trade-off between Nox, Particulate Emission, and Fuel Consumption of a Heavy Duty Diesel Engine', SAE Paper \#2008-01-2500, 2008.

[6] Kitano, K, Sakata, I. and Clark, R., 'Effects of GTL Fuel Properties on DI Diesel Combustion', SAE Paper\#200501-3763, 2005.

[7] Bruno, T. J. and Baibourine, E. "Comparison of BiomassDerived Turbine Fuels with the Composition-Explicit Distillation Curve Method," Energy and Fuels, revised for publication March 2011, publication data forthcoming.

[8] Shonnard, D.R., Williams, L. and Kalnes, T.N., 'Camelina Derived Jet Fuel and Diesel: Sustainable Advanced Biofuels', Environmental Progress and Sustainable Energy, Vol. 29, No. 3, October 2010.

[9] Moses, C.A. "Comparative Evaluation of Semi-Synthetic Jet Fuels," CRC Report Project No. AV-2-04a, Sept., 2008.

[10] A. D. Mathes, J. J. Ries, P. A. Caton, J. S. Cowart, D. Luning Prak, L. J. Hamilton. Binary Mixtures of Branched and Aromatic Pure Component Fuels as Surrogates for Future Diesel Fuels, SAE Transactions, Journal of Fuels and Lubricants, 2010-01-2188, December 2010, 3:794 809.

[11] American Society of Testing and Materials, Book of Standards. Combustion Characteristics; Manufactured Carbon and Graphite Products; Catalysts. Volume 05.05, 2010.

[12] Murphy, M. J., Taylor, J. D., and McCormick, R. L. "Compendium of Experimental Cetane Number Data," National Renewable Energy Laboratory Report NREL/SR-540-36805, September 2004.

[13] Puckett, A. D. and Caudle, B. H. "Ignition Qualities of Hydrocarbons in the Diesel Fuel Boiling Range," Bureau Mines Information Circular 7474, 1948.

[14] American Society of Testing and Materials, Book of Standards. Petroleum Products and Lubricants. Volume 05.01, 2010.

[15] American Society of Testing and Materials, Book of Standards. Petroleum Products and Lubricants (II). Volume 05.02, 2010.

[16]P.J. Linstrom and W.G. Mallard, Eds., NIST Chemistry WebBook, NIST Standard Reference Database Number 69, National Institute of Standards and Technology, Gaithersburg MD, 20899, http://webbook.nist.gov.

[17] Heywood, J.B. Internal Combustion Engine Fundamentals, McGraw Hill, 1988.

[18] Woschni, G. "Universally Applicable Equation for the Instantaneous Heat Transfer Coefficient in the Internal Combustion Engine,", SAE paper \#670931, SAE Transactions, vol. 76, 1967.

[19] Chun, K. M., Heywood, J. B., and Keck, J. C. "Prediction of Knock Occurrence in a Spark-Ignition Engine," Twenty-Second Symposium on Combustion, The Combustion Institute, 1988.

[20] C. K. Westbrook, W. J. Pitz, O. Herbinet, H. J. Curran and E. J. Silke, "A Detailed Chemical Kinetic Reaction Mechanism for n-Alkane Hydrocarbons from n-Octane to n-Hexadecane," Combust. Flame 156 (1) (2009) 181-199.

[21] Curran, H. J., Fisher, E. M., Glaude, P. A., Marinov, N. M., Pitz, W. J., Westbrook, C. K., Layton, D. W., Flynn, P. F., Durrett, R. P., zur Loye, A. O., Akinyemi, O. C., Dryer, F. L. "Detailed Chemical Kinetic Modeling of Diesel Combustion with Oxygenated Fuels," SAE Paper \#2001-01-0653, 2001. 
[22] Westbrook, C. K., Pitz, W. J., and Curran, H. J. "Chemical Kinetic Modeling Study of the Effects of Oxygenated Hydrocarbons on Soot Emissions from Diesel Engines," J. Phys. Chem. A, 110, 2006, 6912 - 6922.

[23] M. Mehl, W. J. Pitz, C. K. Westbrook and H. J. Curran, "Kinetic Modeling of Gasoline Surrogate Components and Mixtures under Engine Conditions," Proc. Combust. Inst. 33 (1) (2011) 193-200.

[24] Caton, P. A., Hamilton, L. J., and Cowart, J. S. "Understanding Ignition Delay Effects with Pure Component Fuels in a Single Cylinder Diesel Engine," ASME Journal of Gas Turbines and Power, 2010, in press.

[25] Flynn, P. F., Durrett, R. P., Hunter, G. L., zur Loye, A. O., Akinyemi, O. C., Dec, J. E., and Westbrook, C. K., "Diesel Combustion: An Integrated View Combining
Laser Diagnostics, Chemical Kinetics, and Empirical Validation”, SAE Paper \#1999-01-0509, 1999.

[26] Curran, H. J., Fisher, E. M., Glaude, P. A., Marinov, N. M., Pitz, W. J., Westbrook, C. K., Layton, D. W., Flynn, P. F., Durrett, R. P., zur Loye, A. O., Akinyemi, O. C., Dryer, F. L., "Detailed Chemical Kinetic Modeling of Diesel Combustion with Oxygenated Fuels", SAE Paper \#2001-01-0653, 2001.

[27] Westbrook, C. K., Pitz, W. J., and Curran, H. J., "Chemical Kinetic Modeling Study of the Effects of Oxygenated Hydrocarbons on Soot Emissions from Diesel Engines", J. Phys. Chem. A, 110, 2006, 6912 - 6922.

[28] Westbrook, C.K. and Pitz, W.J., "Chemical Kinetic Modeling of Combustion of Practical Hydrocarbon Fuels", SAE Technical Paper \#890990, 1989. 
ANNEX A

Properties of pure components, surrogate mixtures, synthetic and conventional fuels ${ }^{1}$

\begin{tabular}{|c|c|c|c|c|c|c|}
\hline \multicolumn{2}{|l|}{ Class and Formula } & $\begin{array}{c}\sigma^{2} \\
(\mathrm{mN} / \mathrm{m})\end{array}$ & $\begin{array}{c}\mathrm{v} \\
\left(\mathrm{mm}^{2} / \mathrm{s}\right)\end{array}$ & $\begin{array}{c}\rho^{3} \\
\left(\mathrm{~kg} / \mathrm{m}^{3}\right)\end{array}$ & cetane & $\begin{array}{c}\text { LHV } \\
(\mathrm{MJ} / \mathrm{kg})\end{array}$ \\
\hline \multicolumn{7}{|l|}{ Baseline Fuel } \\
\hline n-hexadecane & $\left(\mathrm{C}_{16} \mathrm{H}_{34}\right)$ & 26.3 & $4.47 \pm 0.003$ & 774 & 100 & 43.9 \\
\hline \multicolumn{7}{|l|}{ Aromatic Additive } \\
\hline toluene & $\left(\mathrm{C}_{7} \mathrm{H}_{8}\right)$ & 27.9 & $0.656 \pm 0.0002$ & 867 & -5 & 40.5 \\
\hline \multicolumn{7}{|c|}{ Binary Mixtures (by volume) } \\
\hline \multicolumn{2}{|c|}{$50 \%$ toluene in hexadecane } & 26.6 & $1.31 \pm 0.0009$ & 817 & 62.3 & 42.3 \\
\hline \multicolumn{2}{|c|}{$70 \%$ toluene in hexadecane } & 27.1 & $0.953 \pm 0.0005$ & 836 & - & 41.6 \\
\hline \multicolumn{2}{|c|}{$80 \%$ toluene in hexadecane } & $27.4(4)$ & $0.831 \pm 0.0003$ & 846 & 19.7 & 41.3 \\
\hline \multicolumn{7}{|l|}{ Conventional Fuels } \\
\hline Diesel & $\mathrm{C}_{13.5}$ "D" & 26.9 & $3.94 \pm 0.005$ & 856 & 44 & 42.6 \\
\hline JP-5 & $\mathrm{C}_{12.2}$ “J" & 24.9 & $1.85 \pm 0.001$ & 800 & 46.2 & 43.2 \\
\hline \multicolumn{7}{|l|}{ Synthetic Fuels } \\
\hline "STF" (FT) & $\mathrm{C}_{11.0}$ "1" & 28.3 & $2.75 \pm 0.018$ & 865 & 21.3 & 42.6 \\
\hline “Lansol 50" (FT) & $\mathrm{C}_{13.4}$ "2" & 25.8 & $3.79 \pm 0.002$ & 778 & 72.8 & $\mathrm{~N} / \mathrm{A}$ \\
\hline “Sasol” (FT) & $\mathrm{C}_{14.2}$ "3" & 25.3 & $3.98 \pm 0.010$ & 772 & 76.1 & $\mathrm{~N} / \mathrm{A}$ \\
\hline "Shell GTL" (FT) & $\mathrm{C}_{9.4} \quad$ "4" & 22.6 & $1.18 \pm 0.013$ & 733 & 57.9 & 42.5 \\
\hline "S5" (FT) & $\mathrm{C}_{11.6} " 5 "$ & 23.5 & $2.14 \pm 0.001$ & 760 & 67.1 & 44.5 \\
\hline
\end{tabular}

1. A detailed explanation of the measurement procedures can be found in Ref. [1].

2. Accuracy specifications for surface tension are $\pm 0.1 \mathrm{mN} / \mathrm{m}$ for all measurements.

3. Accuracy specifications for density are $\pm 0.1 \mathrm{~kg} / \mathrm{m}^{3}$ for all measurements.

4. Surface tension value for $80 \%$ toluene blend interpolated from $70 \%$ toluene blend and measured value for $85 \%$ toluene blend $(27.6 \mathrm{mN} / \mathrm{m})$. 